\title{
ENDOGENOUS BUSINESS CYCLES AND GROWTH
}

\author{
KLAUS WÄLDE \\ CESIFo Working PAPER No. 920 \\ CAtegory 5: Fiscal Policy, Macroeconomics and Growth \\ APRIL 2003
}

An electronic version of the paper may be downloaded

- from the SSRN website: www.SSRN.com

- from the CESifo website: www.CESifo.de 


\title{
ENDOGENOUS BUSINESS CYCLES AND GROWTH
}

\begin{abstract}
Current explanations why a growing economy necessarily goes through booms and recessions predict countercyclical R\&D investment. As this is very controversial from an empirical perspective, a stochastic Poisson model of endogenous business cycles and growth is presented where the determinants of the cyclical behaviour of $R \& D$ investment are analytically studied. Providing an explicit expression for the expected length of a cycle shows that high frequency fluctuations can indeed be understood by this approach. It is also shown how small technological improvements translate into large aggregate fluctuations.
\end{abstract}

JEL Code: E32, O41.

Keywords: endogenous fluctuations and growth, uncertainty under continuous time.

\author{
Klaus Wälde \\ Department of Economics \\ University of Dresden \\ 01062 Dresden \\ Germany \\ klaus@waelde.com
}

I thank seminar participants in Copenhagen, Munich, Magdeburg, Louvain-la-Neuve, Tilburg and Zürich, Raouf Boucekkine, David de la Croix, Rodolphe Dos Santos Ferreira, Arlington Fink, Stefan Huschens, Patrick Kehoe, Omar Licandro, Huw Lloyd-Ellis, Edward Prescott and especially Sjak Smulders for helpful suggestions and discussions. 


\section{Introduction}

Why do growing economies experience booms and recessions? Traditional answers to this question mainly stress exogenous shocks or non-linearities whose effects are analyzed in stationary economies. Recently, however, several authors have proposed mechanisms that allow to understand both short-run fluctuations and long-run growth in a unified setup. Francois and Lloyd-Ellis (forthcoming) show how bunching of innovation can occur in a quality-ladder growth model. Deterministic cyclical growth results. Freeman, Hong and Peled (1999) show how the introduction of new technologies that require prior accumulation of research experience leads to deterministic cyclical growth as well. The "portfolio approach" by Bental and Peled (1996), Matsuyama (1999, 2001) and Wälde (2002) stresses how the choice of investors between financing capital accumulation and $R \& D$ and implied endogenous jumps in productivity leads to cyclical deterministic growth in Matsuyama's work or cyclical stochastic growth in models of Bental and Peled and Wälde.

A common prediction of these models is a countercyclical allocation of resources to R\&D. In periods of high growth of GDP, few resources are allocated to $R \& D$. With low growth, resource allocation to $R \& D$ is high. Empirically, this prediction is disputed. Some authors find support (Francois and Lloyd-Ellis, forthcoming), some remain inconclusive (Saint-Paul, 1993) while others find evidence against procyclical investment into R\&D (Geroski and Walters, 1995; Fatás, 2000, Wälde and Woitek, 2003).

Given this empirically unclear picture and the seemingly counter-factual prediction of existing models, the first objective of the present paper is to clarify the determinants of the cyclical behaviour of $R \& D$ investment. As the paper is in the tradition of the portfolio approach, it builds its explanation of endogenous fluctuations on investment decisions of individuals who can use their savings to finance capital accumulation or R\&D. As a consequence, determinants of the individual portfolio choice are, upon aggregation, determinants of aggregate cyclical behaviour of R\&D. Shadow prices of capital, the riskiness of $\mathrm{R} \& \mathrm{D}$ and individual dividend payments in case of successful R\&D all play a role.

On the equilibrium path we analyze, relative shadow prices and the riskiness of R\&D is constant. As in our setup dividend payments to successful R\&D increase over the cycle, individuals are induced to shift more and more resources to $R \& D$ as the economy grows. $R \& D$ investment that grows as the economy grows implies procyclical $R \& D$ investment. In a more general perspective, i.e. on equilibrium paths resulting for other parameter values than the one chosen here, the arrival rate and relative shadow prices change over the cycle. R\&D investment can then be procyclical at the beginning 
of the cycle but countercyclical towards the end. This helps to understand contradicting empirical evidence cited above.

Apart from a different prediction concerning cyclical behaviour of R\&D investment, the present paper also stresses a "less drastic" mechanism why growing economies fluctuate. While Matsuyama builds his explanation on a one-period patent protection for new varieties, Bental and Peled assume new technologies to be common knowledge after one period. Here, capital accumulation and $R \& D$ take place in equilibrium as well. As long as risky $R \& D$ is not successful, the economy accumulates capital at a decreasing growth rate resulting from decreasing returns to capital accumulation. When research is successful, a better capital good is available and total factor productivity increases, i.e. a "technology jump" occurs. ${ }^{1}$ Returns to capital accumulation go up and a boom results. As in other work, successful research increases TFP. This increase by itself, however, is enough for booms and recessions and no limited patent protection or sudden common knowledge of a technology is required.

The third objective of the present paper is to understand wether large jumps in technology are required to understand realistic aggregate fluctuations. By presenting a continuous-time model, a closed from solution is available for the entire transition path towards (some kind of) long-run steady state for certain parameter values and despite aggregate uncertainty. This allows to analytically analyze the expected growth rate and the expected length and amplitude of cycles. It turns out that small jumps can cause large aggregate fluctuations.

A further contribution lies in clarifying what type of fluctuations can be understood by the portfolio approach to economic fluctuations. It is sometimes argued that this approach is useful for understanding fluctuations of low frequency but not high frequency fluctuations like business cycles. With an analytical expression for the expected length it can be shown that high frequency fluctuations can well be understood by the portfolio approach to economic fluctuations.

Technically, the paper extends the literature on stochastic continuous time models. The majority of the contributions to this literature use Brownian motion as their source of uncertainty (e.g. Serrat, 2001). The present paper uses Poisson uncertainty as occational jumps are more appropriate for modeling cyclical growth. Poisson uncertainty has been used in finance (e.g. Duffie et. al. 2000) and in the economics literature by e.g. Farzin

\footnotetext{
${ }^{1}$ Following the suggestion of Edward Prescott, the term technology jump will be used to distinguish endogenous discrete changes in (total factor or labour) productivity from exogenous shocks to productivity.
} 
et. al. (1998), Hassett and Metcalf (1999) and Venegas-Martínez (2001). A textbook treatment is in Dixit and Pindyck (1994).

\section{The model}

\subsection{Technologies}

Technological progress is labour augmenting and embodied in capital. A capital good $K_{j}$ of vintage $j$ allows workers to produce with a labour productivity of $A^{j}$, where $A>1$ is a constant productivity parameter. Hence, a more modern vintage $j+1$ implies a labour productivity that is $A$ times higher than labour productivity of vintage $j$. The production function corresponding to this capital good reads

$$
Y_{j}=K_{j}^{\alpha}\left(A^{j} L_{j}\right)^{1-\alpha} .
$$

The amount of labour allocated to this capital good is denoted by $L_{j}, 0<$ $\alpha<1$ is the output elasticity of capital. The sum of labour employment $L_{j}$ per vintage equals aggregate constant labour supply, $\Sigma_{j=0}^{q} L_{j}=L$, where $q$ is the most advanced vintage currently available.

Independently of which vintage is used, the same type of output is produced. Aggregate output is used for producing consumption goods $C$, investment goods $I$ and it is used as an input $R$ for doing $\mathrm{R} \& \mathrm{D}$,

$$
C+I+R=Y=\Sigma_{j=0}^{q} Y_{j} .
$$

All activities in this economy take place under perfect competition. Good $Y$ will be chosen as numeraire. Its price and the price of the consumption, investment and research good will therefore be identical,

$$
p_{Y}=p_{c}=p_{I}=p_{R}
$$

and constant throughout the paper; we will nevertheless use price variables at various places (and not normalize to unity) as this makes some relationships more transparent.

The objective of $R \& D$ is to develop capital goods that yield a higher labour productivity than existing capital goods. R\&D is an uncertain activity which is modeled by the Poisson process $q$ (as in Aghion and Howitt, 1992 or Aghion, 2002). The probability per unit of time $d t$ of successful R\&D is given by $\lambda d t$, where $\lambda$ is the arrival rate of the process $q$. This arrival rate is an increasing function of the amount of resources $R$ used for R\&D,

$$
\lambda=\frac{R}{D} f\left(\frac{R}{D}\right)=\left(\frac{R}{D}\right)^{1-\gamma}, \quad 0<\gamma<1 .
$$


On the firm level, there are constant returns to scale and firms choose resources $R$, taking the "difficulty" function $D$ and the externality $f($.$) as$ given. At the sectoral level, $f($.$) implies decreasing returns to scale. The$ parameter $\gamma$ can be thought of as close to but different from zero. ${ }^{2}$

The exogenous function $D$ captures the "difficulty" to make an invention, as in Segerstrom (1998). Given a certain amount of resources $R$, the probability to find a better capital good is lower, the higher the difficulty $D$. The primary objective is to remove the well-known scale effect (e.g. Jones, 1995) in the present model. We will therefore assume that the difficulty increases in the value $K^{c}$ of the observed capital stock, i.e. the capital stock measured in units of the consumption good,

$$
D=D_{0} K^{c}, \quad D_{0}>0 .
$$

As we will see later, growth of the capital stock $K^{c}$ can be split into an (unbounded) trend component driven by better technologies, i.e. increases in $q$, and into a (bounded) cyclical component. Including the trend component in the difficulty function captures the fact that more resources are required to find better technologies at a constant arrival rate, the more discoveries have been made in the past. A lot of empirically support is available for this specification both on the micro- and macro level (Segerstrom, 2002; Jones 1995). The capital stock $K^{c}$ and therefore the difficulty $D$ also increases (up to an upper bound) due to the cyclical component of $K^{c}$. This latter assumption is made primarily for analytical convenience. It will in particularly allow us to compute explicit expressions for the expected arrival rate of new technologies and thereby the expected length of a cycle and the expected growth rate. This in turn allows us to explicitly study determinants of these quantities. With these expressions in mind, one can then be confident that the basic relationships hold for similar specifications of the difficulty function as well.

When R\&D is successful, $q$ increases to $q+1$ and a first prototype of a production unit that yields a labour productivity of $A^{q+1}$ becomes available. In more conventional quality ladder models, output of successful research is modeled as an intangible good, a blueprint. Owners of the blueprint sell goods constructed accordingly and obtain profits due to some market power. These profits are used to cover R\&D costs. Here, engineers actually construct a first machine that implies this higher labour productivity. Instead of thinking about how a new good or variety can be produced, researchers build one. ${ }^{3}$ This allows us to understand $R \& D$ in a decentralized economy as a perfectly competitive process: Those who have financed $\mathrm{R} \& \mathrm{D}$ obtain a tangible good, a production unit, whose (expected discounted) capital rewards

\footnotetext{
${ }^{2}$ We will see later why attention is restricted to $0<\gamma<1$.

${ }^{3}$ One can think of this prototype as a pilot plant in the sense of Rosenberg (1994).
} 
obtained under perfect competition cover R\&D costs. Hence, no monopoly profits are required.

Concerning the size of the first machine resulting from successful research, we assume it equals a constant share of the current capital stock,

$$
\kappa=\kappa_{0} K^{c}, \quad 0<\kappa_{0} \ll 1 .
$$

When Intel or AMD develop a new processor, when Nokia develops a new cell-phone, total dividend payments are always a very small but constant percentage $\kappa_{0}$ of the capital stock $K^{c}$, no matter how much innovations or how much capital accumulation took place before. An alternative specification would keep productivity and payments at a constant level, $\kappa=$ constant, i.e. a new technology always has the same size. In a growing economy, total dividend payments from new technologies relative to the capital stock would permanently fall. Given this alternative, the specification in (6) is more convincing.

Each vintage of capital is subject to depreciation at the constant rate $\delta$. If investment in vintage $j$ exceeds depreciation, the capital stock of this vintage increases in a deterministic way,

$$
d K_{j}=\left(I_{j}-\delta K_{j}\right) d t, \quad j=0 \ldots q .
$$

When research is successful, the capital stock of the next vintage $q+1$ increases discretely by the size $\kappa$ of the first new machine of vintage $q+1$,

$$
d K_{q+1}=\kappa d q .
$$

Afterwards, (7) would apply to the vintages $j=0 \ldots q+1 .^{4}$

Before describing households, we derive some straightforward equilibrium properties that both simplify the presentation of the production side and, more importantly, the derivation of the budget constraint of households in the next section.

Allowing labour to be mobile across vintages $j=0 \ldots q$ such that wage rates equalize, total output of the economy can be represented by a simple Cobb-Douglas production function (cf. appendix 7.1)

$$
Y=K^{\alpha} L^{1-\alpha}
$$

\footnotetext{
${ }^{4}$ Formally, this equation is a stochastic differential equation driven by the Poisson process $q$ whose arrival rate $\lambda$ is given in (4). The increment $d q$ of this process can either be 0 or 1 . Successful R\&D means $d q=1$.
} 
Vintage specific capital stocks have been aggregated to an aggregate capital index $K$,

$$
\begin{gathered}
K=K_{0}+B K_{1}+\ldots+B^{q} K_{q}=\Sigma_{j=0}^{q} B^{j} K_{j}, \\
\text { where } \quad B \equiv A^{\frac{1-\alpha}{\alpha}} .
\end{gathered}
$$

If $K_{0}$ is thought of as the "number of machines" of vintage $0, K$ gives the number of machines of vintage 0 that would be required to produce the same output $Y$ as with the current mix of vintages.

Given that the price of an investment good does not depend on where this investment good is used, that depreciation is the same for all investment goods and given that value marginal productivities,

$$
w_{j}^{K}=p_{c} \frac{\partial Y}{\partial K} B^{j}
$$

are highest for the most advanced vintage, investment takes place only in the currently most advanced vintage $q, I_{j}=0 \forall j<q, I_{q}=I$. Hence, the evolution of the aggregate capital index $K$ follows from (7) and (8) by applying Ito's Lemma to (10),

$$
d K=\left(B^{q} I-\delta K\right) d t+B^{q+1} \kappa d q .
$$

The capital stock increases continuously as a function of effective investment $B^{q} I$ minus depreciation. ${ }^{5}$ As the prototype increases the capital stock of vintage $q+1$ in case of successful research by $\kappa$, it increases the capital index (10) by $B^{q+1} \kappa$.

As long as investment is positive, the price $v_{q}$ of an installed unit of the most recent vintage of capital equals the price of an investment good, $v_{q}=p_{I}$. As different vintages are perfect substitutes in production (10), prices of different vintages are linked to each other by

$$
p_{I}=v_{q}=B^{q-j} v_{j}, \quad \forall j=0 \ldots q .
$$

Further, the price $p_{K}$ of one efficiency unit of capital (which corresponds to one unit of capital of vintage 0 ) is a decreasing function of the most advanced vintage $q$,

$$
p_{K}=B^{-q} p_{I}
$$

This also reflects the term $B^{q}$ in the capital accumulation equation (13) and provides a link between the capital index $K$ and the capital stock $K^{c}$

\footnotetext{
${ }^{5}$ This is similar to Solow-type vintage models of e.g. Greenwood, Hercowitz and Krusell $(1997,2000)$.
} 
as observed in the data. Multiplying the capital index by the price of one efficiency unit of capital and dividing by the price of the consumption good (which equals the price of the investment good) gives the value of the capital stock in terms of the consumption good,

$$
K^{c} \equiv \frac{p_{K}}{p_{I}} K=B^{-q} K .
$$

This quantity will play an important role when looking later at the empirical predictions of the model.

\subsection{Households}

There is a discrete finite number of households in this economy. Each household is sufficiently small to neglect the effects of own behaviour on aggregate variables. Households maximize expected utility $U(t)$ given by the sum of instantaneous utility $u($.$) resulting from consumption flows c(\tau)$, discounted at the time preference rate $\rho$,

$$
U(t)=E_{t} \int_{t}^{\infty} e^{-\rho[\tau-t]} u(c(\tau)) d \tau,
$$

where the instantaneous utility function $u($.$) is characterized by constant$ relative risk aversion,

$$
u(c(\tau))=\frac{c(\tau)^{1-\sigma}-1}{1-\sigma}, \quad \sigma>0 .
$$

For saving purposes, a household can buy capital and finance R\&D. When she buys capital, her wealth $a$ in terms of the consumption good increases in a deterministic and continuous way. This increase depends on the difference between real capital and labour income $r a+w$ minus real $\mathrm{R} \& \mathrm{D}$ investment $i$ and real expenditure $c$ for consumption. This is the " $d t$-term" on the right hand side of her budget constraint (which is derived in appendix 7.2),

$$
d a=(r a+w-i-c) d t+\left(\kappa \frac{i}{R}-s a\right) d q,
$$

where the interest rate is given by

$$
r=B^{q} \frac{\partial Y}{\partial K}-\delta .
$$

When financing R\&D, i.e. when $i$ is positive, successful research changes her wealth in a discrete way, as shown by the "dq-term" in (19). Total 
dividend payments after a successful research project depend on the price and the size $\kappa$ of the prototype. As $\kappa$, once developed, is the most modern vintage, its price equals by (14) the price of the investment good. Hence by (3), total dividend payments in terms of the consumption good are given by $\kappa$. These payments need to be divided among investors in the successful project. We assume a simple "division rule": A household receives the same share of total dividend payments of the successful research project that she has contributed to financing this project. As R\&D is undertaken under perfect competition, the sum of individual real $\mathrm{R} \& \mathrm{D}$ investment $i$ equals resources $R$ from (2) allocated to the R\&D sector. The household therefore receives the share $i / R$.

A negative effect of successful research stems from the devaluation of capital. When a new vintage is found, i.e. when $q$ increases by one, the price of older vintages relative to the consumption good fall as by (14) and (3) $v_{j} / p_{c}=B^{-(q-j)}$. Capital owners therefore experience a certain reduction in their real wealth. The share of assets that is "lost" due to this devaluation is denoted by $s$ and given by ${ }^{6}$

$$
s=\frac{B-1}{B}
$$

\section{Solving the model}

A household's choice variables are the consumption flow $c$ and real R\&D investment $i$. By choosing consumption, the household solves her consumptionsavings problem. By choosing R\&D investment, she determines the amount of savings going to capital accumulation, i.e. she solves the portfolio problem. One optimality condition describes the evolution of consumption by a Keynes-Ramsey rule. The second one is an arbitrage condition describing the optimal allocation of savings to capital accumulation and R\&D. These two optimality conditions, aggregated over households in an appropriate way, together with the expression for the arrival rate (4) and an equation describing capital accumulation similar to (13) with (2) describe equilibrium of this economy (given initial conditions for the capital stock and consumption.) The next subsection presents four such equations.

\footnotetext{
${ }^{6}$ Greenwood, Hercowitz and Krusell (1997, p. 361), analyzing the long-run effects of technological change limited to investment goods, distinguish between economic depreciation (which would be $s$ here) and physical depreciation (corresponding to $\delta$ ).
} 


\subsection{The cyclical components}

We first focus on understanding the cyclical components of our growth paths. One can split trajectories $K$ and $C$ of the capital index and aggregate consumption into trend components $A^{q / \alpha}$ and $A^{q}$ and cyclical components $\hat{K}$ and $\hat{C}$ according to

$$
K \equiv \hat{K} A^{q / \alpha}, \quad C \equiv \hat{C} A^{q}
$$

Trend components are not identical due to the vintage structure of capital. We will nevertheless eventually analyze a balanced cyclical growth path where $K^{c}$ from (16) (and not $K$ ) and $C$ grow at the same expected rate. With this specification, cyclical components are without trend.

Expressed in our cyclical components (22), the Keynes-Ramsey rule is (cf. appendix 7.3)

$$
-\frac{u^{\prime \prime}(\hat{C})}{u^{\prime}(\hat{C})} d \hat{C}=\left\{r-\rho-\lambda\left[1-(1-s) \frac{u^{\prime}(A \tilde{\hat{C}})}{u^{\prime}(\hat{C})}\right]\right\} d t-\frac{u^{\prime \prime}(\hat{C})}{u^{\prime}(\hat{C})}\{\tilde{\hat{C}}-\hat{C}\} d q,
$$

Consumption rises in a continuous fashion (the $d t$-term) when the interest rate exceeds the time preference rate and the arrival rate times the expression in squared brackets. ${ }^{7}$ With an arrival rate of zero, this is the well-known relationship from deterministic models. With a positive arrival rate, if all wealth was lost in case of successful research, i.e. assuming $s=1$ for interpretational purposes, the interest rate would have to exceed the sum of the time preference rate and the arrival rate in order for consumption to grow. This reflects the fact that consumption is only postponed if returns $r$ compensate for the risk of losing all wealth. When the economic devaluation $s$ is small, wealth is not entirely lost and consumption is postponed also for lower returns $r$. The extent to which a change in $s$ influences the level of returns required for consumption growth depends on the ratio $u^{\prime}(A \tilde{\hat{C}}) / u^{\prime}(\hat{C})$ of marginal utility from consumption after and before successful research. ${ }^{8}$ This ratio equals by the first order condition for consumption the ratio of shadow prices of capital after and before successful research. With a high shadow price of capital after $\mathrm{R} \& \mathrm{D}$, the growth rate of consumption rises simply because successful $\mathrm{R} \& \mathrm{D}$ is

\footnotetext{
${ }^{7}$ As introduced in (22), the cyclical component of a variable $X$ is denoted by $\hat{X}$. Where no ambiguity arises, we will nevertheless talk about e.g. consumption $\hat{C}$ rather than (correctly) the cyclical component $\hat{C}$ of consumption in order to avoid too much repetition.

${ }^{8} \mathrm{~A}$ tilde $(\sim)$ denotes the value of a quantity immediately after successful research.
} 
desirable. ${ }^{9}$ The $d q$-term gives discrete changes in case of successful R\&D. It is tautological, however, and (the cyclical component of) consumption after successful R\&D, $\tilde{\hat{C}}$, needs to be determined in an alternative way.

As appendix 7.3.1 shows, the first order condition for $R \& D$ is satisfied if the certain return from capital accumulation equals the expected return from R\&D,

$$
u^{\prime}(\hat{C})=\lambda u^{\prime}(A \tilde{\hat{C}}) \kappa / R=u^{\prime}(A \tilde{\hat{C}}) \lambda^{-\gamma /(1-\gamma)} \kappa_{0} / D_{0}
$$

The certain return is given by the shadow price of wealth $a$ on the LHS (which by the first order condition for consumption equals marginal utility from current consumption). The expected gain from a marginal unit of savings into R\&D on the RHS is given by the arrival rate times the shadow price of wealth after successful research (which equals marginal utility from consumption after successful research) times "marginal dividend payment" $\kappa / R$. The second equality uses (4), (5) and (6).

Equation (4), rewritten in order to obtain the amount of resources required for R\&D as a function of the arrival rate $\lambda$, with (5), (16) and (22) gives the cyclical component $\hat{R}$ of $\mathrm{R} \& \mathrm{D}$ resources,

$$
\hat{R} \equiv A^{-q} R=\lambda^{1 /(1-\gamma)} D_{0} \hat{K} .
$$

The final equation combines (13), describing the evolution of the capital index, with the goods market clearing condition (2) and uses (22). Letting $\hat{Y}=\hat{K}^{a} L^{1-\alpha}$ describe the cyclical component of GDP, it reads

$$
d \hat{K}=\{\hat{Y}-\hat{R}-\hat{C}-\delta \hat{K}\} d t+\left\{A^{-1 / \alpha}+A^{-1} \kappa_{0}-1\right\} \hat{K} d q .
$$

The deterministic $d t$-term is self-explanatory. The stochastic $d q$-term shows that the change in the capital stock is given by the difference between the new capital stock $\left(A^{-1 / \alpha}+A^{-1} \kappa_{0}\right) \hat{K}$ and the old capital stock $\hat{K}$. The new capital stock equals the old capital stock times $A^{-1 / \alpha}$, which is a consequence of the detrending rule (22), plus the size of the new machine. As the new machine by (6) is proportional to the observed capital stock before successful $\mathrm{R} \& \mathrm{D}$, its size after successful R\&D is reduced by the factor $A$.

Equations (23)-(26), given initial conditions, describe the equilibrium of our economy. Given this system, we now have to understand whether a unique solution exists and what its properties are. A formal proof is beyond the scope of this paper and will be done elsewhere. It would have to follow the

\footnotetext{
${ }^{9}$ When returns to R\&D are very high, the expression in squared brackets can even be negative and the presence of an $\mathrm{R} \& \mathrm{D}$ process has a positive effect on consumption growth.
} 
literature on functional differential equations (e.g. Hale and Verduyn, 1993) due to the retarded term $\tilde{\hat{C}}$ in (23). Intuitively, it is easy to understand, however, that a solution to (23)-(26) exists indeed and is unique.

If we replace the arrival rate in (23) by the expression resulting from (24), we have a differential equation which gives the change of consumption as a function of the capital index, consumption itself, exogenous quantities and $\tilde{\hat{C}}(t)$, the cyclical component of consumption after successful R\&D. Equation (26), after having inserted (25) with the arrival rate again replaced by the expression from (24) gives us the change of the capital index as a function of the capital index, consumption, exogenous quantities and $\tilde{\hat{C}}(t)$. If we knew $\tilde{\hat{C}}(t)$, we would have a two-dimensional differential equation system in $\hat{K}(t)$ and $\hat{C}(t)$ which, provided initial conditions $\hat{K}_{0}$ and $\hat{C}_{0}$, gives a unique path $\{\hat{K}(t), \hat{C}(t)\}$.

The crucial step in understanding existence and uniqueness of such a solution is that on the optimal path (in an analogy, think of the saddle path in an optimal growth model), i.e. on the path where the initial consumption level $\hat{C}_{0}$ is optimally chosen, consumption is a function of the current capital index only (and not of $q$ ),

$$
\hat{C}=\hat{C}(\hat{K}(t))
$$

As a consequence, the consumption level $\tilde{\hat{C}}(t)$ after successful research obeys the same functional relationship (27) as any other consumption level. It is determined by $\tilde{\hat{C}}(t)=\hat{C}(\tilde{\hat{K}}(t))$, i.e. the consumption level corresponding to the capital stock $\tilde{\hat{K}}(t)$ after successful research. As this capital stock can be computed from (26) by setting $d t=0$ and $d q=1$, one just needs to insert $\tilde{\hat{K}}(t)$ into $(27)$ to obtain $\tilde{\hat{C}}(t)$. The jump in consumption is therefore such that the system jumps from $(\hat{K}, \hat{C})$ to $(\tilde{\hat{K}}, \tilde{\hat{C}})$ where both capitalconsumption pairs are on the optimal path $\hat{C}(\hat{K}(t))$. This completes the illustration of existence and uniqueness of a solution of the above system. The next section proves formally (for a certain parameter set) that such a path actually exists.

\subsection{A linear policy rule}

One can proof the existence of a unique solution as just informally described and derive its properties for a certain set of parameters. By focusing on this 
solution, we can derive many interesting predictions. We argue later and it will become clear that many findings hold more generally.

Theorem 1 If the share of capital in GDP equals the inverse of the intertemporal elasticity of substitution, i.e. if $\alpha=\sigma$, the arrival rate $\lambda$ is constant and given by

$$
\lambda=\left(\xi^{-\sigma} \kappa_{0} D_{0}^{-1}\right)^{(1-\gamma) / \gamma}
$$

where

$$
\xi=\kappa_{0}+B^{-1}
$$

Further, the cyclical component of consumption is a linear function of the cyclical component of the capital index,

$$
\hat{C}=\Psi \hat{K}
$$

where $\Psi$ is a constant as well,

$$
\Psi=\frac{\rho+\lambda\left[1-(1-s) \xi^{-\sigma}\right]+(1-\sigma) \delta}{\sigma}-\left(\lambda D_{0}\right)^{1 /(1-\gamma)}
$$

Finally, the jump in capital and consumption is given by

$$
\frac{\tilde{\hat{C}}}{\hat{C}}=\frac{\tilde{\hat{K}}}{\hat{K}}=A^{-1} \xi .
$$

Proof. cf. appendix 7.4 .

Clearly, the results to be presented hold exactly only for $\alpha=\sigma$. How reasonable is such an assumption (made e.g. also in deterministic models of Xie, 1991, 1994)? When the capital share is understood in a narrow sense, i.e. when $\alpha=1 / 3$, the intertemporal elasticity of substitution $\varepsilon$ equals $\varepsilon=1 / \sigma=3$. Compared to usual average estimates of $\varepsilon$ lying between 0 and 1 (e.g. Vissing-Jørgensen, 2002), this appears high. Taking $\alpha$ to capture the output elasticity of capital in a broad sense (including human capital), i.e. $2 / 3<\alpha<1$, the intertemporal elasticity of substitution lies between 1 and 1.5. Allowing for household heterogeneity and estimating $\varepsilon$ for households that hold assets (in contrast to those that do not), Vissing-Jørgensen found values of $\varepsilon$ in this range. Hence, with $2 / 3<\alpha<1$, the implied value for $\varepsilon$ appears reasonable.

Independently of what the appropriate value for $\alpha$ is exactly, however, assuming $\alpha=\sigma$ is required only for obtaining analytical results. Many findings for this case should hold for parameter values $\alpha \neq \sigma$ as well, only that they have to be found numerically. Results found here could therefore be seen as a benchmark case for broader numerical investigations. 


\subsection{Equilibrium}

For $\alpha=\sigma$, equilibrium of our economy can be described by the consumption rule (30) and the differential equation (26) for the cyclical component of capital, which, with (25) and (29), can be written as

$$
d \hat{K}=\{\hat{Y}-\hat{C}-\hat{\delta} \hat{K}\} d t+\left\{A^{-1} \xi-1\right\} \hat{K} d q
$$

where $\hat{\delta}=\delta+\lambda^{1 /(1-\gamma)} D_{0}$. Figure 1 illustrates the evolution of capital and consumption. It plots $\hat{K}$ on the horizontal and $\hat{C}$ on the vertical axis. Zeromotion lines $d \hat{K}=0$ and $d \hat{C}=0$ follow for $d q=0$ from (33) and from (23) with (24) and (25). In both cases, equilibrium properties (28) and (32) have been used. The fact that equilibrium properties are used for plotting zero motion lines is typical of systems with retarded arguments as $\tilde{\hat{C}}$. Zero motion lines dependent on which trajectory the economy finds itself on. In the solution of deterministic control problems, zero motion lines can be computed before the equilibrium trajectory is known. Here, equilibrium has to be found first and zero-motion lines have an illustrative purpose only. Nevertheless, zero-motion lines have the usual shape and laws of motion indicated by arrows are identical to standard Ramsey growth models. This allows us to describe a typical cycle of our growing economy as follows:

Let the economy start with some historically given capital index $\hat{K}_{0}$. With consumption given by $\hat{C}_{0}$, the economy is on the equilibrium path and approaches the steady state as long as research is not successful, i.e. $d q=0$. The capital stock and GDP grow, research is being undertaken. At some point, research is successful, a better vintage is available and $q$ increases by one. The new level of the cyclical component $\hat{K}$ of the capital stock by (26) amounts to $\tilde{\hat{K}}=\left(A^{-1} \kappa_{0}+A^{-1 / \alpha}\right) \hat{K}$ and changes due to two factors: First, it decreases because of the factor $A^{-1 / \alpha}<1$, originating from the detrending rule (22). Second, it increases by the size of the new machine, i.e. by $A^{-1} \kappa_{0}$. Overall, the capital index drops if the relative size $\kappa_{0}$ of the new machine is small enough. As this is the only empirically reasonable assumption, we set

$$
A^{-1} \xi=A^{-1} \kappa_{0}+A^{-1 / \alpha}<1
$$

and the economy finds itself at a point $(\tilde{\hat{K}}, \tilde{\hat{C}})$ after successful research, where $\tilde{\hat{K}}<\hat{K}$. There, it starts growing again through accumulating capital of the new vintage and it approaches the steady state until the next jump occurs. 
Result 2 Equilibrium cyclical growth takes place on a path where capital is accumulated and REDD is undertaken and where better vintages causing fluctuations and growth come at random points in time. The expected length between two vintages and whether new vintages are developed at all is endogenously determined by the households' investment decisions.

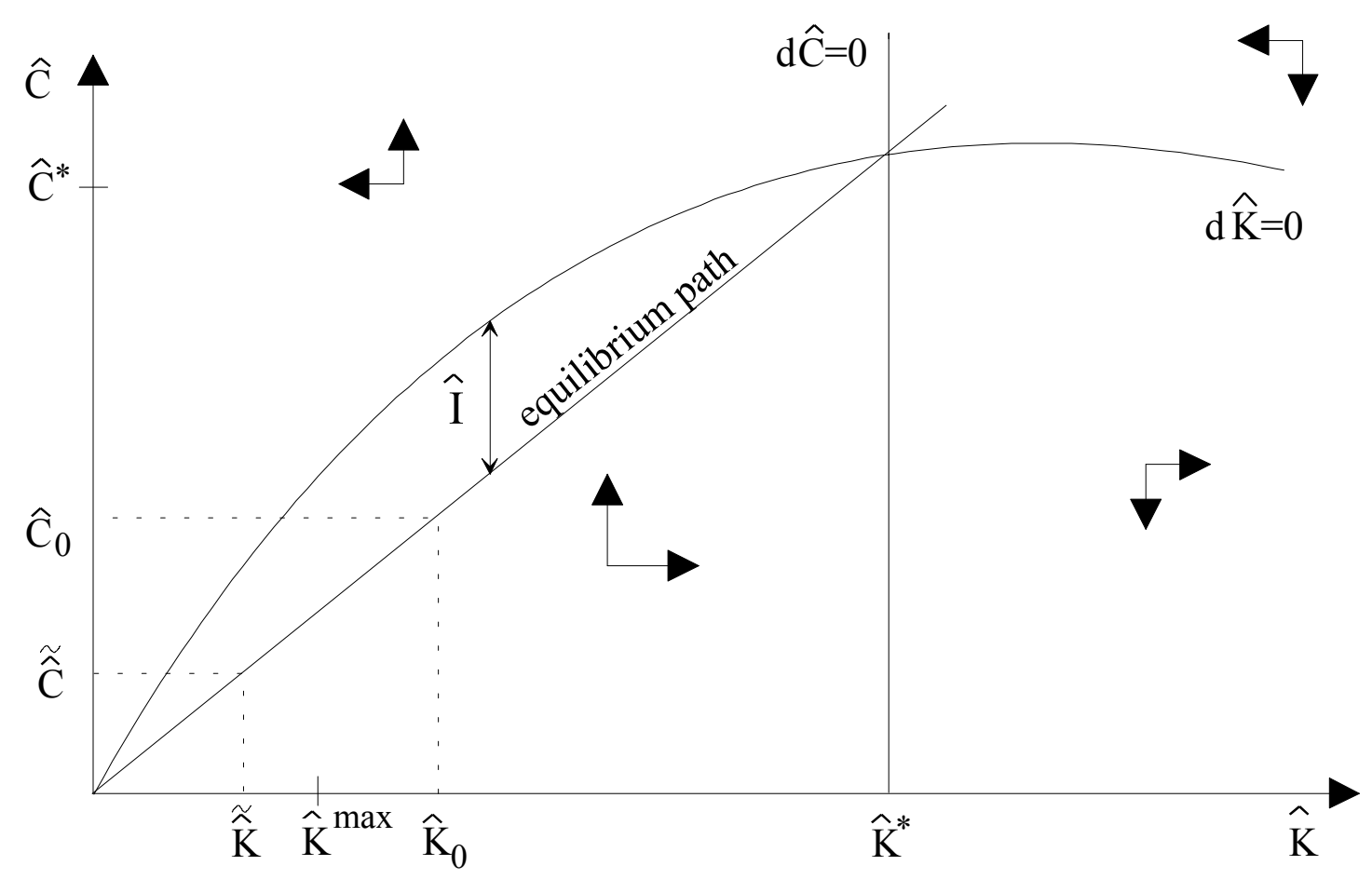

Figure 1: The equilibrium path in a phase diagram

Returning to the informal proof of a unique solution to the system (23) - (26), this phase diagram illustrates (and the theorem has proven) that on the optimal path there is a functional relationship as in (27) indeed and that $\tilde{\hat{C}}(t)=\hat{C}(\tilde{\hat{K}}(t))$, i.e. a jump in the capital stock implies a jump in consumption such that the economy jumps to some other point on the path on which it found itself before the jump.

This process describes a distribution of the capital index $\hat{K}$ with a range ] $0, \hat{K}^{*}$. The boundaries of this range are intuitively clear: With each jump, the capital index $\hat{K}$ moves to the origin. As by (32) each jump is proportional, the origin will never be reached. When no jump takes place, the capital index 
approaches the steady state. As this approach is asymptotic, the upper bound is never reached, either.

The level of the capital index $\tilde{\hat{K}}$ after a jump is bounded as well,

$$
0<\tilde{\hat{K}}<A^{-1} \xi \hat{K}^{*} \equiv \tilde{\hat{K}}^{\max } .
$$

By (32), it is strictly positive as the capital index $\hat{K}$ before the jump is positive. It is also strictly smaller than the level where it would end up when jumping back from the steady state $\hat{K}^{*}$ (as the steady state is never reached).

It remains to be shown that the limiting distribution of $\hat{K}$ is stationary. More precisely, letting the economy start with some $\hat{K}_{0}$ and looking at $\hat{K}(T)$ for $T \rightarrow \infty$, the distribution of $\hat{K}(T)$ is neither a function of time $T$ or $\hat{K}_{0}$. A well-known theorem states that a distribution with limited range is completely characterized by its integer moments (e.g. Casella and Berger, 1990, th. 2.3.3.). As it is fairly straightforward (following Garcia and Griego, 1994) to prove that for $T \rightarrow \infty$ all (integer) moments of $\hat{K}^{1-\alpha}$ are constant, the distribution of $\hat{K}^{1-\alpha}$ is unique and stationery. As a consequence, distributions of all functions of $\hat{K}^{1-\alpha}$ considered here (i.e. $\hat{K}, \hat{C}, \hat{Y}$ etc.) are stationary as well.

\section{Plausibility of equilibrium paths}

\subsection{Short-run fluctuations}

Let us look at the evolution of variables as they are actually "observed" by re-transforming cyclical components into observed variables. One realization of actual variables is depicted in figure 2 .

The capital index $K$ increases smoothly as long as no jump occurs, as by (22) and with $d q=0$ it is proportional to $\hat{K}$. As $\hat{K}$ approaches the steady state with an ever decreasing growth rate, it has an upper bound which it never reaches. The same therefore holds for $K$. When a jump occurs, the capital index unambiguously increases according to (13) by $\tilde{K}-K=B^{q+1} \kappa$. With (6) and (16), we obtain

$$
\frac{\tilde{K}}{K}=B \kappa_{0}+1=B \xi>1
$$

An immediate implication of the time path of $K$ for GDP, following from (9), is that GDP increases smoothly as well when research is not successful 
and jumps as a result of successful research by

$$
\frac{\tilde{Y}}{Y}=\left(\frac{\tilde{K}}{K}\right)^{\alpha}=(B \xi)^{\alpha}>1 .
$$

The same holds true for real wages as by the Cobb-Douglas structure in (9) they are a constant share of GDP, $w / p_{c}=(1-\alpha) Y / L$. Figure 2 illustrates that $K, Y$ and $w$ qualitatively behave in the same way. The jump is not the same as (36) and (37) show.
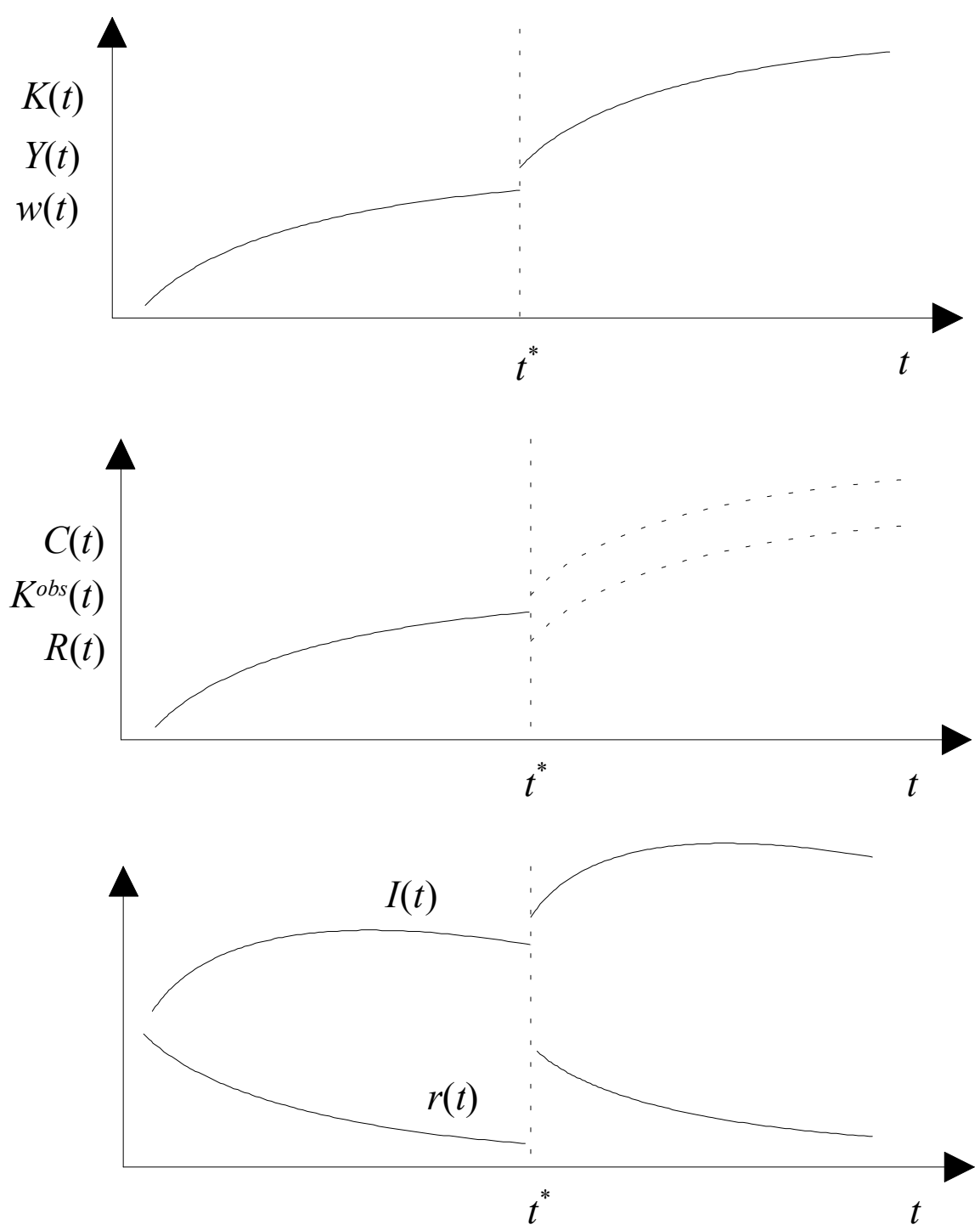

Figure 2: Qualitative properties of cycles 
Quantitatively, the predicted jumps in $K, Y$ and $w$ are small as they stem from the discovery of the new prototype in research. Compared to the existing aggregate capital index, this is small. In terms of the model and (36), the increase of e.g. $K$ is by $B \kappa_{0} \%$.

Consumption $C$, the observed capital stock $K^{c}$ from (16) and R\&D investment $R$ are all proportional to $\hat{K}$ (cf. appendix 7.5). In periods without jumps, they behave qualitatively identical to, say, GDP. Computing the jump of these variables, however, gives

$$
\frac{\tilde{R}}{R}=\frac{\tilde{C}}{C}=\frac{\tilde{K}^{c}}{K^{c}}=\xi=B^{-1} \frac{\tilde{K}}{K} .
$$

The jump is lower than the jump of the capital index and can be a drop, as $\xi$ can be smaller than unity. With plausible parameter values, i.e. with $\kappa_{0}$ very small and $B$ within a reasonable range (to be discussed later), $\xi$ is smaller than unity indeed. Investment in $\mathrm{R} \& \mathrm{D}$, consumption and the observed capital stock drop after an innovation. Given the present model, a recession, measured by negative growth rates of consumption, can be a good sign. Individuals postpone consumption as a new technology promises higher returns to capital accumulation. ${ }^{10}$

The cyclical component of investment $\hat{I}=\hat{Y}-\hat{C}-\hat{\delta} \hat{K}$ is given by the distance between the equilibrium path and the zero-motion line in figure 1. As observed investment $I$ by applying $(22)$ is proportional to $\hat{I}$, its behaviour over the cycle is identical to $\hat{I}$. If the upper bound $\tilde{\hat{K}}^{\max }$ for the capital index after the jump in (35) is lower than the capital stock where $\hat{I}$ is at its maximum, and the capital stock an instant before the jump is larger than this capital stock, investment is non-monotonic even without jumps. When a jump occurs, investment unambiguously increases (cf. appendix 7.5).

Finally, the interest rate (20) with (9) and (22) is $r=\alpha(L / \hat{K})^{1-\alpha}-\delta$. It jumps when research is successful and $\hat{K}$ falls. This induces a boom, i.e. a phase of growth rates above average. The interest rate falls smoothly as $\hat{K}$ increases and the economy eventually has growth rates below average, i.e. it enters a recession. Overall, the interest rate is without trend.

\subsection{Long-run growth}

We measure the growth rate between today in $t$ and some future point $T$ by the difference in logarithms $g_{T, t} \equiv \ln Y(T)-\ln Y(t)$. Inserting the produc-

\footnotetext{
${ }^{10}$ One should be careful with this interpretation as it also relies on the assumption that, due to $\sigma=\alpha$, the intertemporal elasticity of substitution is larger than unity. A drop in consumption would not hold for lower elasticities of substitution.
} 
tion function (9) and using the martingale property of $q(t)-\lambda t$, gives an expected growth rate per unit of time of (cf. appendix 7.6)

$$
E g_{t} \equiv \frac{E_{t} g_{T, t}}{T-t}=\lambda \ln A+\alpha \frac{E_{t} \ln \hat{K}(T)-\ln \hat{K}(t)}{T-t} .
$$

This expression shows how the expected growth rate depends on the initial capital index $\hat{K}(t)$. As the nominator of the second term is bounded and the denominator goes to infinity when the future point $T$ is sufficiently far in the future, we focus on the first term $\lambda \ln A$ as the central determinant of expected growth.

Result 3 From (28) and (29), the arrival rate is given by

$$
\lambda=\left(\frac{\kappa_{0}}{\left[\kappa_{0}+B^{-1}\right]^{\sigma} D_{0}}\right)^{(1-\gamma) / \gamma} .
$$

For decreasing returns to scale in the R\&D sector $(0<\gamma<1)$, the arrival rate increases in $A$ and falls in $D_{0}$, i.e. it increases when interventions are more important and become less difficult. If in addition $(1-\sigma) \kappa_{0}+B^{-1}>0$ (cf. appendix 7.7), which holds on our equilibrium path where $\sigma=\alpha$, the arrival rate increases when dividend payments increase,

$$
\frac{\partial \lambda}{\partial A}>0, \quad \frac{\partial \lambda}{\partial D_{0}}<0, \quad \frac{\partial \lambda}{\partial \kappa_{0}}>0
$$

There are scale effects neither in the arrival rate nor in the expected growth rate which is also due to the difficulty function (5). Other parameters that sometimes appear in growth rates (e.g. the time preference rate or the depreciation rate) do not have a growth effect. They have a level effect though, as they affect the behavior of cyclical components via (31).

In order to fully understand why these results hold only for decreasing returns to scale and why the effect of dividend payment $\kappa_{0}$ is ambiguous, consider again the household's first order conditions for R\&D investment (24), $u^{\prime}(\hat{C})=\lambda u^{\prime}(A \hat{\hat{C}}) \kappa / R$. For a a given capital stock $\hat{K}$ and with (30), certain returns from capital accumulation, $u^{\prime}(\hat{C})=(\Psi \hat{K})^{-\sigma}$ are independent of R\&D investment $R$ and can therefore be depicted as a horizontal line in 
the following figure. ${ }^{11}$

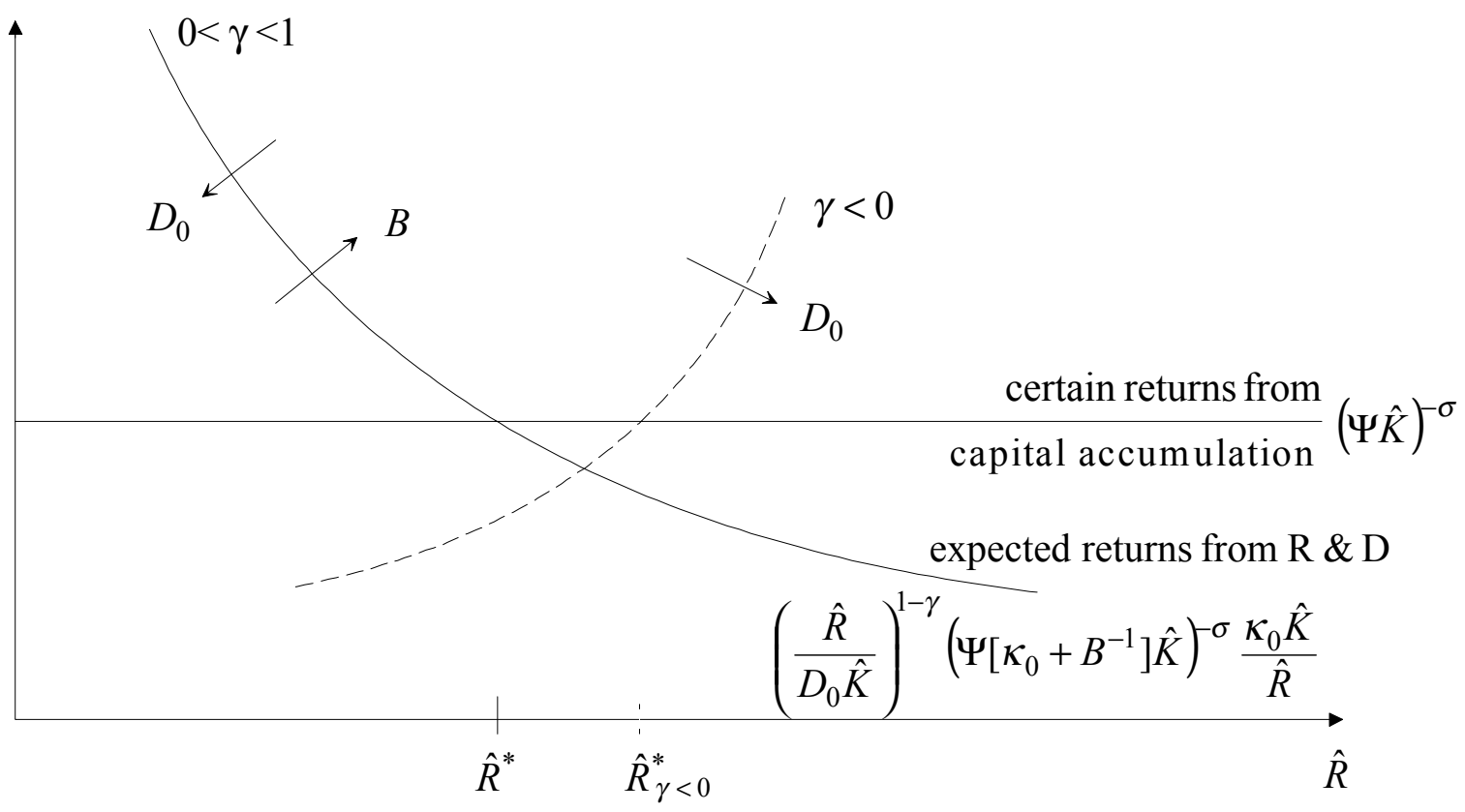

Figure 3: Equilibrium R\&D investment

Expressing expected returns with (4), (5), (16), (22) and (25) as $\lambda u^{\prime}(A \tilde{\hat{C}}) \kappa / R=$ $\left(\hat{R} /\left(D_{0} \hat{K}\right)\right)^{1-\gamma}\left(\Psi\left[\kappa_{0}+B^{-1}\right] \hat{K}\right)^{-\sigma} \kappa_{0} \hat{K} / \hat{R}$ shows that expected returns fall in $\hat{R}$ for decreasing returns to scale in the $\mathrm{R} \& \mathrm{D}$ sector, i.e. for $0<\gamma<1$. Decreasing returns therefore guarantee stability of optimal $R \& D$ investment $\hat{R}^{*}$. For increasing returns $(\gamma<0)$, expected returns to R\&D would increase in $R$ (as the dashed line shows) and the equilibrium point at $\hat{R}_{\gamma<0}^{*}$ would be unstable. For $\gamma=0$, expected returns would be horizontal as well and agents would find it optimal to invest all savings either into R\&D or into capital accumulation. R\&D investment would be countercyclical (Wälde, 2002).

An increase in difficulty $D_{0}$ decreases expected returns, as the expression in the figure immediately shows, and $R \& D$ investment falls. ${ }^{12}$ If expected returns increased in $\hat{R}$ for $\gamma<0$, this result would reverse. As increasing returns to R\&D must be ruled out because of the stability aspect just described, we will limit all subsequent discussion to the case of decreasing returns. A

\footnotetext{
${ }^{11}$ I am grateful to Sjak Smulders for having suggested the presentation of such a figure.

${ }^{12}$ The effect of any parameter change on $\Psi$ can be neglected as it has the same effect on certain returns and on expected returns. It therefore cancels out.
} 
larger $\kappa_{0}$ increases expected returns as it increases dividend payments $\kappa_{0} \hat{K}$. It decreases expected returns as the shadow price $\left(\Psi\left[\kappa_{0}+B^{-1}\right] \hat{K}\right)^{-\sigma}$ of capital falls. Which effect is stronger depends on the elasticity of substitution parameter $\sigma$.

\section{The nature of cycles}

\subsection{Cyclical behaviour of R\&D investment}

We analyze cyclical properties of endogenous variables by using an inequality attributed to Čebyšev (e.g. Mitrinović, 1970, ch. 2.5, th. 10): Let two functions obey $f^{\prime}(x) g^{\prime}(x) \gtrless 0$ on an interval $] a, b\left[\right.$. Then $\int_{a}^{b} p(x) d x \int_{a}^{b} p(x) f(x) g(x) d x$ $\gtrless \int_{a}^{b} p(x) f(x) d x \int_{a}^{b} p(x) g(x) d x$ for an integrable function $p(x)>0$ on ]$a, b[$. Applying this to our question, let $X$ be a random variable with density $p(X)$ and support $[a, b]$ and $f(X)$ and $g(X)$ two transformations for which $f^{\prime}(x) g^{\prime}(x) \gtrless 0$ for all realizations $x$ of $X$. Then $\int_{a}^{b} p(x) d x=1$ and the inequality says $E f(X) g(X) \gtrless E f(X) E g(X)$ which is identical to saying that the covariance of these transformed random variables is given by $\operatorname{cov}(f(X), g(X)) \gtrless 0$. Simply speaking, when two variables "move in the same direction" $\left(f^{\prime}(x)\right.$ and $g^{\prime}(x)$ are both either positive or negative), their covariance and correlation coefficient are positive. In terms of business cycle analysis, letting $g(X)$ represent output, $f(X)$ is procyclical.

As a first application of Cebyšev's inequality, consider the correlation of the interest rate with output. As before and as is custom in empirical work, we consider cyclical components only. We therefore detrend output by applying (22) to (9) and removing the resulting trend term $A^{q}$. For the trendless interest rate, only (20) is applied in order to get an expression in terms of $\hat{K}$. Taking $\hat{K}$ as our random variable $X$ and the cyclical component of GDP and of the interest rate as transformations, $f(\hat{K})=\hat{K}^{\alpha} L^{1-\alpha}$ and $g(\hat{K})=\alpha(L / \hat{K})^{1-\alpha}-\delta$, a negative correlation is found. The intuition, given Čbyšev's inequality is simple: The interest rate falls in the capital stock, GDP rises. As they move in opposite directions, they are negatively correlated, i.e. the interest rate is countercyclical.

While the interest rate falls in the capital stock in all models with standard neoclassical production functions, models with shocks to total factor productivity often imply (e.g. King and Rebelo, 1999, p.939) that GDP and the interest rate are positively correlated, in contrast to what is empirically observed. The present model departs in one important way from other se- 
tups, causing this result: Jumps of total factor productivity cause long-run growth and do not play any role in determining the cyclical component. In fact, the cyclical behaviour of the interest rate and the cyclical component of GDP is entirely determined by $\hat{K}$. Hence, this unambiguous countercyclical behaviour of the interest rate. In more traditional models, shocks to total factor productivity are central to understanding cyclical behaviour. As both GDP and the interest rate increase in TFP, a procyclical relationship is usually found.

Now use Čebyšev's inequality to understand why R\&D investment and GDP are positively correlated here and negatively correlated in the existing literature on endogenous fluctuations and growth. If we express the cyclical components of R\&D investment $R$ and GDP $Y$ as a function of the random variable $\hat{K}$, we can deduce the sign of their correlation coefficient by checking the sign of $\hat{R}^{\prime}(\hat{K}) \hat{Y}^{\prime}(\hat{K})$. As $\hat{Y}^{\prime}(\hat{K})>0$ and on our equilibrium path, $\hat{R}^{\prime}(\hat{K})>0$ by $(26)$ and $(28), \mathrm{R} \& \mathrm{D}$ is procyclical.

To understand why $\hat{R}$ increases as $\hat{K}$ increases, look again at figure 3 . An increase in $\hat{K}$ decreases the shadow price of capital before and after the jump, $(\Psi \hat{K})^{-\sigma}$ and $\left(\Psi\left[\kappa_{0}+B^{-1}\right] \hat{K}\right)^{-\sigma}$, in the same way. Changes in shadow prices are therefore neutral and do not affect R\&D investment. An increase in $\hat{K}$ increases expected returns, i.e. the expected returns curve shifts outward, as dividend payments $\kappa_{0} \hat{K}$ rise. At the same time, it decreases expected returns through the increase in difficulty $D_{0} \hat{K}$ that decreases that arrival rate. Due to decreasing returns in the $R \& D$ sector, the dividend payment effect is stronger than the difficulty effect. The expected returns curve shifts outward and R\&D investment rises.

Result 4 Dividend payments and the difficulty to invent increase as capital is accumulated. The investment encouraging effect of higher dividend payments overcompensates the discouraging effect of higher difficulty due to decreasing returns in the R\&D sector. R\&D investment is procyclical.

More generally speaking, if e.g. $\alpha \neq \sigma$, the relative shadow price $(\Psi \hat{K})^{-\sigma}$ $/\left(\Psi\left[\kappa_{0}+B^{-1}\right] \hat{K}\right)^{-\sigma}$ is not independent of $\hat{K}$. If it is a decreasing function of $\hat{K}$, procyclical R\&D investment would be preserved. If, however, it is strongly increasing in $\hat{K}, \mathrm{R} \& \mathrm{D}$ investment would eventually become countercyclical. 


\subsection{Jumps and aggregate fluctuations}

The aggregate impact of jumps can be measured by the length and the amplitude of fluctuations. As on our equilibrium path the arrival rate $\lambda$ in (40) is constant, the expected length of a cycle is simply its inverse $\lambda^{-1}$,

$$
\text { ELength }=\lambda^{-1}=\left(\frac{\left[\kappa_{0}+B^{-1}\right]^{\sigma} D_{0}}{\kappa_{0}}\right)^{(1-\gamma) / \gamma} .
$$

The amplitude of a cycle can be measured, corresponding to the approach in empirical work, by the distance between the maximum and the minimum of the $\log$ of the cyclical component of GDP, $\hat{Y}=\hat{K}^{\alpha} L^{1-\alpha}$. As the GDP ratio is given by $\hat{Y} / \tilde{\hat{Y}}=(\hat{K} / \tilde{\hat{K}})^{\alpha}$, the distance is with $(34)$

$$
\text { Amplitude }=\ln (\hat{Y} / \tilde{\hat{Y}})=\alpha \ln \left(A^{-1} \kappa_{0}+A^{-1 / \alpha}\right)^{-1} \geq \ln A
$$

where the approximation used that $\kappa_{0}$ is close to zero.

These two expressions show that small jumps can have large effects. Jumps are small in a first sense, as they affect only the new vintage $q+1$ and not old vintages $0 \ldots q$. Nevertheless, this jump in labor productivity for one vintage translates into an amplitude of aggregate fluctuations of the same order of magnitude. Jumps are small in a second sense when the size $\kappa_{0}$ of the new machine relative to the aggregate capital stock is small. Concerning the expected length, we have another

Result 5 With decreasing returns in $R \mathscr{E} D(0<\gamma<1)$, the expected length of a cycle goes to infinity as the size of the machine goes to zero,

$$
\lim _{\kappa_{0} \rightarrow 0} \text { ELength }=\infty
$$

i.e. small jumps can cause long-lasting aggregate fluctuations.

Understanding this result is straightforward when recalling the discussion of the arrival rate (40). A smaller size $\kappa_{0}$ means smaller dividend payments. Less resources are allocated to $R \& D$ and the arrival rate falls. The expected length of a cycle, being its inverse, increases. The interesting effect is the strong nonlinearity of (41) in $\kappa_{0}$. When $\kappa_{0}$ goes linearly to 0 , the expected length quickly increases. 


\subsection{Which frequencies can we understand?}

Looking at (41), the model seems flexible to capture both high and low frequencies. In order to be reasonable, the model should also on average predict realistic growth rates (39). Taking for illustration purposes the average length of post-World War II business cycles to be 5 years in OECD countries and the average growth rate to be $2 \%$, we obtain two conditions,

$$
\begin{aligned}
\text { ELength } & =\lambda^{-1}=5 \text { years, } \\
E g_{t} & =\lambda \ln A=2 \% .
\end{aligned}
$$

They immediately imply $\ln A=.1 \Leftrightarrow A \approx 1.1$ from inserting $\lambda=.2$ from the first in the second. Given the expression for the expected length (41), one parameter of the remaining $\kappa_{0}, D_{0}$ and $\gamma$ is therefore fixed by (43). (The parameter $\sigma$ is pinned down on our equilibrium path by $\sigma=\alpha$.) As $\gamma$ is limited to lie between 0 and 1 to obtain intuitive comparative static results as discussed in Theorem 3 , and $\kappa_{0}$ should be small following the discussion of (6), $D_{0}$ would have to adjust in order to satisfy (43). Hence,

Result 6 The model can be used to jointly analyze endogenous business cycles and growth.

\section{Conclusion}

The starting point of this paper was the belief that economic fluctuations can originate endogenously from within an economy. R\&D and the development of more efficient production units was presented as one mechanism causing an economy to grow by going through booms and recessions. The mechanism causing fluctuations is endogenous in the sense that the economy could grow (at least up to an upper bound) also without investment in R\&D. It is the intentional choice of investors to have new technologies which causes fluctuations. If no investment took place, no fluctuations would be observed.

The first objective was to clarify the determinants of cyclical behaviour of R\&D investment. In empirically work, R\&D investment tends to be procyclical, while evidence for some countercyclical behaviour of R\&D in a large sense can be found. The present paper has shown that the cyclical behaviour can be understood by analyzing a portfolio decision problem. Understanding the determinants of this decision problem means understanding the cyclical behaviour of R\&D.

The average rate at which new technologies arrive and thereby the expected growth rate of the economy depends, among others, on total dividend 
payments, the increase in labour productivity due to new technologies and the returns to scale in the $\mathrm{R} \& \mathrm{D}$ sector. These determinants also pin down the average length of a cycle. The expression for the expected length of the cycle has shown that small technology jumps in an economy can easily have large effects on the aggregate level. It has also been shown by fixing some parameter values that the model can capture both high frequency fluctuations of 5 years and reasonable annual growth rates of $2 \%$. Business cycles and growth can therefore be jointly understood and studied.

Clearly, there are shortcomings that need to be addressed in future work. By studying the portfolio decision of households further, more could be said about the cyclical behaviour of $R \& D$ expenditure. Alternative specifications for the difficulty function or the division rule could, for example, be taken into account. None of the existing papers on endogenous fluctuations and growth takes unemployment into account. Employment effects of fluctuations, however, are central in policy discussions about business cycles. The model should numerically be solved for a broader class of parameter values. This would expand our understanding of the determinants of endogenous fluctuations. Further, while the length of a cycle is stochastic, each new technology increases labour productivity by the same factor $A$. Introducing a stochastic increase would allow to study the effects of large and small technology jumps in an economy. Finally, extensions to multi-sector economies would yield further insights about the co-movement of sectors over the cycle.

\section{References}

[1] Aghion, P., 2002, Schumpeterian Growth Theory and the Dynamics of Income Inequality. Econometrica 70: 855 - 882.

[2] Aghion, P. and Howitt, P., 1992, A Model of Growth through Creative Destruction. Econometrica 60: 323 - 351.

[3] Bental, B., Peled, D., 1996, The accumulation of wealth and the cyclical generation of new technologies: A Search Theoretic Approach. International Economic Review 37, 687 - 718.

[4] Casella, G., Berger, R. L., 1990, Statistical inference. Duxbury, Pacific Grove, CA.

[5] Dixit, A. K., Pindyck, R. S.,1994, Investment Under Uncertainty. Princeton University Press. 
[6] Duffie, D., Pan, J., Singleton, K., 2000, Transform Analysis and Asset Pricing for Affine Jump-Diffusions. Econometrica 68: 1343 - 1376.

[7] Fatás, A., 2000, Do Business Cycles Cast Long Shadows? Short-Run Persistence and Economic Growth. Journal of Economic Growth 5: 147 - 162.

[8] Farzin, Y.H. , Huisman, K.J.M., Kort, P.M., 1998. Optimal Timing of Technology Adoption. Journal of Economic Dynamics and Control 22: $779-799$.

[9] Francois, P., Lloyd-Ellis, H., forthcoming, Animal Spirits Through Creative Destruction. American Economic Review.

[10] Freeman S., Hong D.-P., Peled D., 1999, Endogenous Cycles and Growth with Indivisible Technological Developments. Review of Economic Dynamics 2, 403 - 432 .

[11] Garcia, M.A., Griego, R.J., 1994, An Elementary Theory of Stochastic Differential Equations Driven by a Poisson Process, Commun. Statist. Stochastic Models 10: 335 - 363.

[12] Geroski, P. A., Walters, C. F., 1995, Innovative Activity over the Business Cycle. Economic Journal 105: 916 - 928.

[13] Greenwood, J., Hercowitz, Z., Krusell, P., 2000, The Role of InvestmentSpecific Technological Change in the Business Cycle. European Economic Review 44: 91 - 115.

[14] Greenwood, J., Hercowitz, Z., Krusell, P., 1997, Long-Run Implications of Investment-Specific Technological Change. American Economic Review: $342-362$.

[15] Hale J. K., Verduyn Lunel S. M., 1993, Introduction to Functional Differential Equations. Springer Verlag. New York.

[16] Hassett K. A., Metcalf G. E., 1999, Investment with Uncertain Tax Policy: Does Random Tax Discourage Investment? The Economic Journal 109 (July): 372 - 393.

[17] Jones, C. I., 1995, Time Series Tests of Endogenous Growth Models. Quarterly Journal of Economics 110: 495 - 525.

[18] King, R. G., Rebelo, S. T., 1999, Resuscitating Real Business Cycles. Handbook of Macroeconomics 1, ch. 14. Elsevier, Amsterdam. 
[19] Matsuyama, K., 2001, Growing through Cycles in an Infinitely Lived Agent Economy. Journal of Economic Theory 100: 220 - 234.

[20] Matsuyama, K., 1999. Growing Through Cycles. Econometrica 67: 335 $-347$.

[21] Mitrinović, D. S., 1970, Analytic Inequalities. Springer-Verlag, Berlin.

[22] Rosenberg, N., 1994, Exploring the Black Box. Technology, Economics, and History. Cambridge University Press.

[23] Saint-Paul, G., 1993, Productivity Growth and the Structure of the Business Cycle. European Economic Review 37: 861 - 883.

[24] Segerstrom P. S., 2002, Intel Economics. mimeo.

[25] Segerstrom P. S., 1998, Endogenous Growth without Scale Effects. American Economic Review 88: 1290 - 1310.

[26] Serrat, A., 2001, A Dynamic Equilibrium Model of International Portfolio Holdings. Econometrica 69: 1467 - 1489.

[27] Venegas-Martínez, F., 2001, Temporary stabilization: A stochastic analysis. Journal of Economic Dynamics and Control 25: 1429 - 1449.

[28] Vissing-Jørgensen, A., 2002, Limited Asset Market Participation and the Elasticity of Intertemporal Substitution. Journal of Political Economy 110: $825-853$.

[29] Wälde, K., 2002, The Economic Determinants of Technology Shocks in a Real Business Cycle Model. Journal of Economic Dynamics and Control 27: $1-28$.

[30] Wälde, K., Woitek, U., 2003, R\&D expenditure in G7 countries and the implications for endogenous fluctuations and growth. CesIfo Discussion paper, (available e.g. at www.waelde.com/publications.html).

[31] Xie, D., 1991, Increasing Returns and Increasing Rates of Growth. Journal of Political Economy 99: 429 - 435.

[32] Xie, D., 1994, Divergence in Economic Performance: Transitional Dynamics with Multiple Equilibria. Journal of Economic Theory 63: 97 112.

\section{Appendix}

available upon request 


\title{
CESifo Working Paper Series
}

\author{
(for full list see www.cesifo.de)
}

852 Gregory D. Hess, The Economic Welfare Cost of Conflict: An Empirical Assessment, February 2003

853 Douglas J. Cumming and Jeffrey G. MacIntosh, Comparative Venture Capital Governance. Private versus Labour Sponsored Venture Capital Funds, February 2003

854 Eckhard Janeba and John Douglas Wilson, Decentralization and International Tax Competition, February 2003

855 Tapio Palokangas, Capital Accumulation and Employment Cycles in a Model of Creative Destruction, February 2003

856 Brendan Walsh, When Unemployment Disappears: Ireland in the 1990s, February 2003

857 Luis H. R. Alvarez and Erkki Koskela, A General Approach to the Stochastic Rotation Problem with Amenity Valuation, February 2003

858 Christian Schultz, Strategic Campaigns and Redistributive Politics, February 2003

859 Ernst Fehr and Joseph Henrich, Is Strong Reciprocity a Maladaptation? On the Evolutionary Foundations of Human Altruism, February 2003

860 Haizhou Huang, Dalia Marin, and Chenggang Xu, Financial Crisis, Economic Recovery and Banking Development in Former Soviet Union Economies, February 2003

861 Pedro Cardoso and Bernard M.S. van Praag, How Sustainable Are Old-age Pensions in a Shrinking Population with Endogenous Labour Supply?, February 2003

862 Volker Meier, Efficient Transfer of Aging Provisions in Private Health Insurance, February 2003

863 Edward Castronova, Theory of the Avatar, February 2003

864 Robert S. Chirinko, Hans van Ees, Harry Garretsen, and Elmer Sterken, Investor Protections and Concentrated Ownership: Assessing Corporate Control Mechanisms in the Netherlands, February 2003

865 Bernard M.S. van Praag and Pedro Cardoso, The Mix Between Pay-as-you-go and Funded Pensions and what Demography has to do with it, February 2003

866 Ernst Fehr, Urs Fischbacher, Bernhard von Rosenbladt, Jürgen Schupp, and Gert G. Wagner, A Nation-Wide Laboratory. Examining Trust and Trustworthiness by Integrating Behavioral Experiments into Representative Survey, February 2003 
867 Frank Heinemann, The Inflationary Impact of Wage Indexation, February 2003

868 Eytan Sheshinski, Bounded Rationality and Socially Optimal Limits on Choice in a Self-Selection Model, February 2003

869 M. Hashem Pesaran, Estimation and Inference in Large Heterogenous Panels with Cross Section Dependence, February 2003

870 Luis H. R. Alvarez and Erkki Koskela, On the Tree-Cutting Problem under Interest Rate and Forest Value Uncertainty, February 2003

871 Norbert Berthold and Rainer Fehn, Unemployment in Germany: Reasons and Remedies, February 2003

872 Clemens Fuest, Bernd Huber, and Philipp Tilleßen, Tax Policy and Entrepreneurship in the Presence of Asymmetric Information in Capital Markets, February 2003

873 Eytan Sheshinski, Optimum and Risk-Class Pricing of Annuities, February 2003

874 Willi Leibfritz, Paul O'Brien and Jean-Christophe Dumont, Effects of Immigration on Labour Markets and Government Budgets - An Overview, February 2003

875 M. Hashem Pesaran and Allan Timmermann, How Costly is it to Ignore Breaks when Forecasting the Direction of a Time Series?, February 2003

876 Thorvaldur Gylfason and Gylfi Zoega, Education, Social Equality and Economic Growth: A View of the Landscape, February 2003

877 Robin Boadway and Jean-François Tremblay, Public Economics and Startup Entrepreneurs, February 2003

878 Erkki Koskela and Roope Uusitalo, The Un-Intended Convergence: How the Finnish Unemployment Reached the European Level, February 2003

879 Robert Fenge and Volker Meier, Pensions and Fertility Incentives, February 2003

880 Eytan Sheshinski, Note on Income Taxation and Occupational Choice, February 2003

881 A B Atkinson, Income Inequality in OECD Countries: Data and Explanations, February 2003

882 Thomas Gehrig and Rune Stenbacka, Venture Cycles: Theory and Evidence, February 2003

883 Ralf Becker and Thomas Hellmann, The Genesis of Venture Capital - Lessons from the German Experience, March 2003

884 Eytan Sheshinski, Note on the Optimum Pricing of Annuities, March 2003

885 Paul De Grauwe and Magdalena Polan, Globalisation and Social Spending, March 2003 
886 F. van der Ploeg, Do Social Policies Harm Employment and Growth?, March 2003

887 Mirjam van Praag, Initial Capital Constraints Hinder Entrepreneurial Venture Performance: An empirical analysis, March 2003

888 Bernard Steunenberg, Coordinating Sectoral Policymaking: Searching for Countervailing Mechanisms in the EU Legislative Process, March 2003

889 Eytan Sheshinski, Optimum Delayed Retirement Credit, March 2003

890 Frederick van der Ploeg, Rolling Back the Public Sector - Differential effects on employment, investment and growth, March 2003

891 Paul De Grauwe and Marc-Alexandre Sénégas, Monetary Policy in EMU when the Transmission is Asymmetric and Uncertain, March 2003

892 Steffen Huck and Kai A. Konrad, Strategic Trade Policy and the Home Bias in Firm Ownership Structure, March 2003

893 Harry Flam, Turkey and the EU: Politics and Economics of Accession, March 2003

894 Mathias Hoffmann and Ronald MacDonald, A Re-examination of the Link between Real Exchange Rates and Real Interest Rate Differentials, March 2003

895 Badi H. Baltagi, Espen Bratberg, and Tor Helge Holmås, A Panel Data Study of Physicians' Labor Supply: The Case of Norway, March 2003

896 Dennis C. Mueller, Rights and Citizenship in the European Union, March 2003

897 Jeremy Edwards, Gains from Trade in Tax Revenue and the Efficiency Case for Trade Taxes, March 2003

898 Rainer Fehn and Thomas Fuchs, Capital Market Institutions and Venture Capital: Do They Affect Unemployment and Labour Demand?, March 2003

899 Ronald MacDonald and Cezary Wójcik, Catching Up: The Role of Demand, Supply and Regulated Price Effects on the Real Exchange Rates of Four Accession Countries, March 2003

900 R. Selten, M. Schreckenberg, T. Pitz, T. Chmura, and S. Kube, Experiments and Simulations on Day-to-Day Route Choice-Behaviour, April 2003

901 Stergios Skaperdas, Restraining the Genuine Homo Economicus: Why the Economy Cannot be Divorced from its Governance, April 2003

902 Yin-Wong Cheung, Menzie D. Chinn, and Antonio Garcia Pascual, What Do We Know about Recent Exchange Rate Models? In-Sample Fit and Out-of-Sample Performance Evaluated, April 2003

903 Mika Widgrén, Enlargements and the Principles of Designing EU - Decision-Making Procedures, April 2003 
904 Phornchanok Cumperayot, Dusting off the Perception of Risk and Returns in FOREX Markets, April 2003

905 Kai A Konrad, Inverse Campaigning, April 2003

906 Lars P. Feld and Stefan Voigt, Economic Growth and Judicial Independence: Cross Country Evidence Using a New Set of Indicators, April 2003

907 Giuseppe Bertola and Pietro Garibaldi, The Structure and History of Italian Unemployment, April 2003

908 Robert A.J. Dur and Otto H. Swank, Producing and Manipulating Information, April 2003

909 Christian Gollier, Collective Risk-Taking Decisions with Heterogeneous Beliefs, April 2003

910 Alexander F Wagner, Mathias Dufour, and Friedrich Schneider, Satisfaction not Guaranteed - Institutions and Satisfaction with Democracy in Western Europe, April 2003

911 Ngo Van Long, Raymond Riezman, and Antoine Soubeyran, Trade, Wage Gaps, and Specific Human Capital Accumulation, April 2003

912 Andrea Goldstein, Privatization in Italy 1993-2002: Goals, Institutions, Outcomes, and Outstanding Issues, April 2003

913 Rajshri Jayaraman and Mandar Oak, The Signaling Role of Municipal Currencies in Local Development, April 2003

914 Volker Grossmann, Managerial Job Assignment and Imperfect Competition in Asymmetric Equilibrium, April 2003

915 Christian Gollier and Richard Zeckhauser, Collective Investment Decision Making with Heterogeneous Time Preferences, April 2003

916 Thomas Moutos and William Scarth, Some Macroeconomic Consequences of Basic Income and Employment Subsidies, April 2003

917 Jan C. van Ours, Has the Dutch Miracle Come to an End?, April 2003

918 Bertil Holmlund, The Rise and Fall of Swedish Unemployment, April 2003

919 Bernd Huber and Marco Runkel, Optimal Design of Intergovernmental Grants under Asymmetric Information, April 2003

920 Klaus Wälde, Endogenous Business Cycles and Growth, April 2003 